\title{
O DESFLORESTAMENTO AO LONGO DA RODOVIA BR-174 (MANAUS/AM - BOA VISTA/RR)
}

\section{The deforestation along the BR-174 road (Manaus / AM - Boa Vista / RR)}

\author{
Eduardo Paschoal Rodrigues \\ Mestre em Ciências do Ambiente e Sustentabilidade na Amazônia /PPGCASA/UFAM \\ Manaus/AM - Brasil \\ edu.pr@ig.com.br \\ Eduardo da Silva Pinheiro \\ Professor no Departamento de Geografia, UFAM \\ Manaus/AM - Brasil \\ pinheiro@ufam.edu.br
}

Artigo recebido para publicação em 02/09/2011 e aceito para publicação em 06/12/2011.

RESUMO: $\quad$ Pesquisas indicam que o processo de desflorestamento na Amazônia está associado à abertura de estradas, uma vez que favorece o fluxo migratório, a ocupação de terras e a exploração de madeiras. $O$ objetivo deste trabalho foi analisar o desflorestamento no entorno $(20 \mathrm{~km})$ da rodovia BR-174 por um periodo de 30 anos (1978-2008). Para analisar o desflorestamento foram utilizadas imagens LANDSAT, dados do INPE/PRODES, dados cartográficos e econômicos e trabalhos de campo. Os resultados demonstraram um crescimento do desflorestamento, passando de 622,15 $\mathrm{km}^{2}$ em 1978 para 2.618,58 $\mathrm{km}^{2}$ em 2008. As principais atividades econômicas dos municípios por onde passa a BR-174, exceto Manaus, estão associadas à agropecuária. Em Manaus, o desflorestamento ocorre principalmente na área urbana. Ainda que a construção da BR-174 esteja associada a processos de desflorestamento, a rodovia possui grande importância para a região, pois foi responsável pela ligação terrestre entre duas capitais do norte do país (Manaus/AM e Boa Vista/RR) e possibilitou formar comunidades onde são desenvolvidas atividades econômicas e sociais. A criação de projetos de desenvolvimento sustentável é o grande desafio dos governos locais, para agregar valor aos empreendimentos existentes e desenvolver novos modelos de uso e ocupação na região.

Palavras-chaves: Amazônia. Desflorestamento. Geoprocessamento. Rodovia.

ABSTRACT: Researches indicate that deforestation in the Amazon is associated with roads constructions, because it favors the migration and therefore the land occupation and wood exploitation. The BR-174 road was built in the 1970s and it was totally paved in 1997. This paper presents the analysis of spatial and temporal change of deforestation in the BR-174 road surroundings (20 km) for a period of 30 years (1978-2008). We used Landsat satellite images, INPE/PRODES data, fieldwork, cartographic and economic data. The results showed a high growth of deforestation rate, from $622.15 \mathrm{~km}^{2}$ in 1978 to $2618.58 \mathrm{~km}^{2}$ in 2008 . Agriculture and cattle rising are the most common economic activities in the cities crossed by the BR174 road, except Manaus, and nowadays it occurs on areas which were previously coverer by forest. In Manaus the deforestation process occurs mainly associated with urban growth. Although the construction of BR-174 is related to deforestation processes, the road has a great importance in the region because 
it turns into possible the connection between the two capitals (Manaus/AM and Boa Vista/RR), and it allowed the creation of new communities with their social and economic activities. Sustainable development projects will be the challenge for local governments, in order to add value to existing projects and develop new models for the land use in the region.

Keywords: Amazon. Deforestation. GIS. BR-174 road.

\section{INTRODUÇÃO}

O desflorestamento na Amazônia brasileira é um processo de natureza complexa para ser atribuído apenas a um único fator (BATISTELA; MORAN, 2007), entretanto segundo Laurance et al. (2001) e Fearnside (2005), a construção e a pavimentação de estradas e a construção de vicinais (ramais) representam um dos principais vetores de desflorestamento na região. Comparando-se os rios e rodovias como meio de transporte, vetores de colonização e eixo de penetração, ambos têm um potencial significativo para irradiar o desflorestamento. Porém, as rodovias são mais efetivas já que possibilitam um fluxo maior e tornam mais rápido o transporte de material, cargas e pessoas, são matrizes para o surgimento de ramais, povoamentos e exploração dos recursos naturais (FEARNSIDE, 2005).

A rodovia BR-174 começou a ser construída na década de 1970 e sua pavimentação total só foi realizada em 1997. Na época, o principal discurso político para a pavimentação desta estrada, foi a possibilidade de escoar os produtos da Zona Franca de Manaus para mercados dos países vizinhos e demais países do hemisfério Norte, além de permitir a ligação entre Manaus/AM e Boa Vista/RR. Simultaneamente à construção da BR-174 o estado do Amazonas incentivou a criação de projetos de assentamentos rurais, que contribuíram para a atração de um fluxo migratório, formado por pequenos agricultores que ocuparam as margens da BR-174 e a estrada de Balbina (AM-240) (OLIVEIRA, 2000).

A ocupação das terras no estado de Roraima data dos tempos coloniais, com a implantação de práticas extrativistas e da pecuária extensiva, ainda que a intenção fosse estimular a agricultura, partin- do do pressuposto de que aquelas terras possuíam boa fertilidade natural (HEMMING, 1990). No início do século XX, mesmo com a implantação dos primeiros núcleos de colonização e dos projetos de assentamentos baseados na agricultura itinerante e extração da madeira como suporte à subsistência, a pecuária permaneceu como atividade primária em Roraima (MELO; UCHOA, 2008). Nos últimos 10 anos, houve um grande fluxo de agropecuaristas no sentido Norte-Sul de Roraima, como conseqüência dos conflitos entre índios e colonos na área da Terra Indígena Raposa-Serra do Sol e pela política oficial de assentamentos ao longo da BR-174 e BR-210, estendo-se pelos municípios de Mucajaí, Novo Paraíso, São Luiz do Anauá até Caroebe (MELO; UCHOA, 2008).

Para Silva; Sá (2003), os fatores de transformação conexos à BR-174 podem atuar tanto como propulsores de desenvolvimento econômico quanto como vetores de pressão e degradação socioambiental, caso os processos não sejam adequadamente controlados. As perspectivas socioeconômicas são seguidas de obras e ocupação da terra, por vezes com planejamento inadequado, ou mesmo sem planejamento que ocasionam impactos ambientais, como, desflorestamento, degradação dos solos, assoreamento de cursos d'água, entre outros. Diante desta dicotomia, surge a necessidade de analise das transformações que ocorreram na cobertura florestal ao longo da rodovia.

Uma vez que a construção e pavimentação de estradas contribuem para o estabelecimento do desflorestamento e a proporção do desflorestamento decai exponencialmente em função da distância das estradas (SOARES FILHO 1998; LAURANCE et al., 2001; SOUZA Jr et al., 2004; FEARNSIDE 2005; FERREIRA et al., 2005), este trabalho almeja responder a duas questões, a saber: A região Amazô- 
nica possui uma variedade de arquiteturas espaciais e complexos fundiários (BATISTELA; MORAN, 2007). Durante vários anos as políticas de ocupação e as práticas econômicas, por vezes predatórias, não consideraram as particularidades ambientais e sociais da região. Neste contexto, desde a década de 1970 até os dias atuais, quais foram as alterações na cobertura florestal do entorno da rodovia BR-174 (Manaus/AM - Boa Vista/RR)? Quais são as principais atividades econômicas nos municípios por onde passa a BR-174 e os possíveis desencadeamentos do desflorestamento?

\section{MATERIAL E MÉTODOS}

\section{Caracterização da área de estudo}

$\mathrm{O}$ estudo foi realizado em uma faixa de 20 $\mathrm{km}$ ao longo da rodovia BR-174 que liga as capitais Manaus/Amazonas e Boa Vista/Roraima (Figura 1). A rodovia interliga os municípios de Manaus, Rio Preto da Eva, Presidente Figueiredo, Rorainópolis, Caracaraí, Iracema, Mucajaí, Boa Vista, Amajari e Pacaraima, além de diversas vilas até a Venezuela.

Figura 1: Localização da área de estudo.

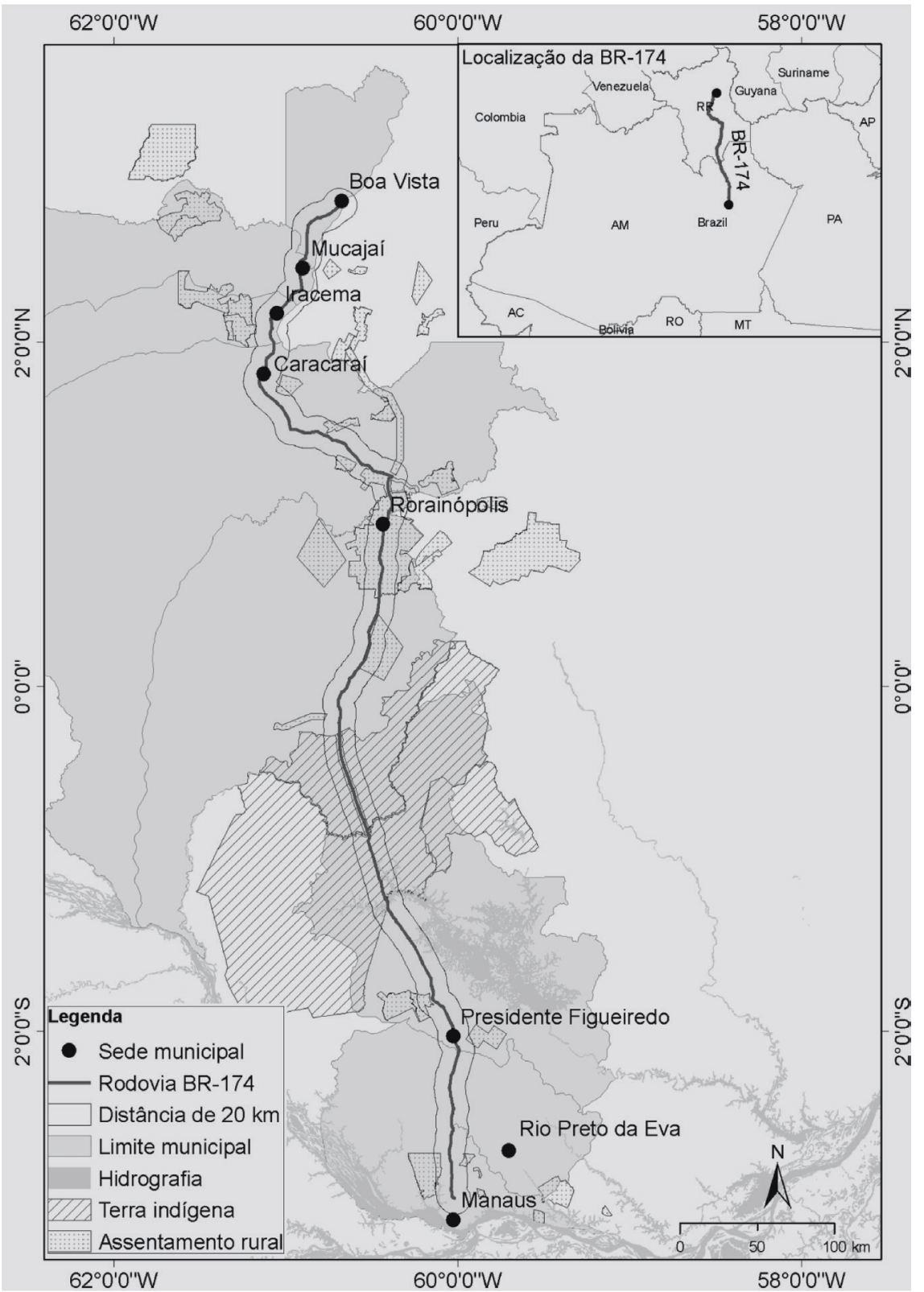




\section{Breve histórico da BR-174}

A rodovia BR-174 teve sua construção iniciada em 1970, mediante o convênio entre o Departamento Nacional de Estradas de Rodagem (DNER) e o Ministério do Exército. No ano de 1977 foi concluída a ligação terrestre entre Manaus e marco BV-8A(fronteira Brasil/Venezuela).

O principal objetivo da construção da BR-174 era consolidar a ligação rodoviária entre Roraima e o restante do Brasil. Esta ligação era extremamente precária, com trafegabilidade na região Sul do estado comprometida, devido às inundações por longos períodos do ano. $\mathrm{O}$ acesso fluvial ao estado, possível apenas até a cidade de Caracaraí/RR, era de forma intermitente, sendo interrompido durante os períodos de baixas vazões do Rio Branco (SILVA; SÁ, 2003).

Devido à dificuldade de navegabilidade e às péssimas condições de trafegabilidades, havia épocas nas quais o acesso à Boa Vista/RR era possível somente por via aérea. Esta configuração estabelecia uma situação de isolamento sazonal em relação ao restante do Brasil e gerava restrições ao desenvolvimento e a economia. Somava-se ainda a precariedade do suprimento de energia elétrica a Roraima, que era atendido por um parque térmico à base de óleo combustível, a partir do Amazonas. Uma modificação neste contexto promoveria ao estado de Roraima uma redução do custo de vida local, estímulo à produção agrícola $\mathrm{e}$ a articulação com o mercado consumidor de Manaus e outras capitais(SILVA; SÁ, 2003).

Em 1994, foi realizada a pavimentação asfáltica do trecho entre Boa Vista e o marco BV- 8A, consolidando a ligação daquela capital com a Venezuela, e, em seguida, o asfaltamento do trecho entre Boa Vista e Caracaraí. Naquele ano, foram iniciadas as obras de melhoria e asfaltamento dos trechos Manaus - Rio Alalaú (na fronteira estadual Amazonas/Roraima), e, Rio Alalaú - Rio Branco (na cidade de Caracaraí) (SILVA; SÁ, 2003). Conforme estes autores, logo após a pavimentação da BR-174, ao contrário do que se esperava, não havia frotas de caminhões para utilizar esta nova rota de exportação. Assim, a vantagem de economizar duas semanas em transporte rodoviário superava o custo de exportar diretamente por navio. No entanto, o discurso relativo a uma rota de caminhão para a Venezuela serviu ao seu propósito de obter apoio político para pavimentar a rodovia.

\section{Os conflitos com os índios Waimiri-Atroari na abertura da BR-174}

A população indígena da etnia Waimiri-Atroari habita uma área entre o norte do Amazonas e o sul de Roraima. A partir do final da década de 1960, o Governo Federal iniciou a ocupação deste território indígena, por meio de projetos de desenvolvimento regional. Entre os anos de 1972 a 1977 as terras indígenas foram atravessadas pela BR-174. Em 1973, após invasões violentas do seu território, a população dos Waimiri-Atroari foi reduzida, de mais de duas mil para 600 pessoas. Em 1983, a população era de apenas 332 indivíduos (BAINES, 1993a). Ainda na década de 1970, ocorreu a implantação da mina para extração de cassiterita e a construção da usina hidrelétrica de Balbina dentro da Terra Indígena (BAINES, 1993b).

Para abrir a BR-174, foi organizada uma operação de "pacificação" dos Waimiri-Atroari pela Fundação Nacional do Índio (FUNAI). Após conflitos interétnicos e uma resistência armada indígena contra as agressões dos invasores, com vários ataques aos funcionários da FUNAI (1970-1987), os Waimiri-Atroari passaram a ser vistos, dentro do indigenismo brasileiro, como um exemplo paradigmático da resistência indígena (BAINES, 1993b).

\section{Aspectos econômicos dos municípios}

Nos municípios por onde passa a BR-174, entre as práticas econômicas, destacam-se a agricultura e a pecuária, com exceção das duas capitais, Boa Vista/ RR e Manaus/AM onde a economia concentra-se em outras atividades. No município de Boa Vista/RR a estrutura produtiva está assentada no setor terciário. A geração de emprego é realizada, sobretudo, pelo setor público, que concentra o maior contingente, seguido pelo setor comercial. A produção primária concentra-se na pecuária, principalmente bovina e na cultura do arroz e milho. No setor secundário, os principais ramos são a atividade madeireira $\left(5.900 \mathrm{~m}^{3} \mathrm{em} 2008\right)$, metalúrgica, alimentícia, oleiro-cerâmico e construção civil (IBGE, 2011). A economia de Manaus/AM está centralizada na indústria de aparelhos eletroeletrônicos, associada à Zona Franca de Manaus. A produção agrícola baseia-se no cultivo de mandioca, cupuaçu, frutas cítricas 
e hortaliças. A produção animal é representada principalmente por frangos, suínos e bovinos (IBGE, 2011).

Em Mucajaí/RR a economia concentra-se na agricultura, produção animal (frangos e bovinos) e na mineração (diamante e ouro). As lavouras somam 1.727 ha, onde são produzidos, em especial: arroz, mandioca, banana, milho, abacaxi, mamão, manga e cupuaçu. A extração de madeira também é um importante elemento na economia local. Em 2008 a produção totalizou $11.000 \mathrm{~m}^{3} \mathrm{em}$ madeira em toras e $9000 \mathrm{~m}^{3}$ em madeira para lenha (IBGE, 2011). No município de Iracema/RR as atividades econômicas concentram-se na agricultura (mandioca, arroz e milho) e na pecuária. Iracema possui o maior rebanho bovino da região estudada (210.501 cabeças). Em Caracaraí/RR a economia é baseada na agricultura de subsistência e no desenvolvimento da pecuária semi-extensiva. Predominam as culturas de arroz, feijão, milho, mandioca e pastagens. Em Rorainópolis/RR, sobressaem as pequenas propriedades agrícolas, oriundas do processo de colonização, sendo que a maior parte dos lotes possui até 100 ha (IBGE, 2009). Na agricultura predominam as culturas de arroz, feijão, milho, mandioca e pastagens. Na extração vegetal foi contabilizado em 2008, $32.500 \mathrm{~m}^{3}$ de madeiras em toras e $11.500 \mathrm{~m}^{3}$ de madeira para lenha (IBGE, 2011).

No estado do Amazonas, o município de Presidente Figueiredo apresenta a economia centrada na mineração (extração de cassiterita). $\mathrm{Na}$ agricultura destaca-se a produção de cupuaçu, mandioca, cana-de-açúcar, arroz, milho, batata doce, laranja, abacaxi, abacate, pupunha, melancia, tucumã e banana. A produção animal é representada pela produção frangos, bovinos e suínos. O extrativismo abastece o setor da construção civil com produtos como madeira e outros materiais. No município de Rio Preto da Eva/AM, a produção agrícola é baseada no cultivo de mandioca, cítricos e hortaliças. Em 2008, extração de madeira de lenha contabilizou $57.752 \mathrm{~m}^{3}$ e a produção de carvão vegetal, 487 toneladas. A criação animal é representada principalmente por frangos, codornas e suínos (IBGE, 2011).

\section{Aspectos da ocupação}

O crescimento populacional dos municípios ligados pela rodovia teve início na década de 1970 (Tabela 1), os migrantes chegaram a Roraima atraídos pelas atividades pecuária e de mineração, pelos projetos de colonização, oportunidades de trabalho em obras e serviços públicos. Nas décadas pós 1970 este crescimento foi prolongado com a tendência pré-rodoviária (BR-174). A distribuição dos fluxos migratórios ocorreu na segunda metade da década de 1970 com a ocupação das margens da rodovia. Na década de 1980, foram abertas vicinais para alojar os novos migrantes que chegavam ao Estado (BARROS, 1996).

No estado do Amazonas, o crescimento populacional está associado principalmente à implantação da Zona Franca de Manaus, em 1967, quando se iniciou um novo ciclo econômico, com a instalação de um parque industrial e a consolidação de um setor terciário baseado na comercialização de produtos importados. Nos últimos trinta anos, a Zona Franca foi responsável pela atração de um grande fluxo migratório do interior do Amazonas e de diferentes regiões do país (OLIVEIRA; SCHOR, 2008). Em conseqüência, a população de Manaus saltou de 311.622 habitantes, na década de 1970, para 1.802.014 em 2010 (Tabela 1).

Tabela 1: Crescimento populacional dos municípios por onde passa a BR-174.

\begin{tabular}{l|r|r|r|r|r|r|r}
\hline \multirow{2}{*}{ Municípios } & \multirow{2}{*}{ Elevação a município } & \multicolumn{7}{|c}{ População / ano } \\
\cline { 3 - 8 } & & $\mathbf{1 9 7 0}$ & $\mathbf{1 9 8 0}$ & $\mathbf{1 9 9 1}$ & $\mathbf{1 9 9 6}$ & \multicolumn{1}{c}{$\mathbf{2 0 0 0}$} & \multicolumn{1}{c}{$\mathbf{2 0 1 0}$} \\
\hline Boa Vista & 1988 & - & - & 144.249 & 162.828 & 200.586 & 284.313 \\
\hline Mucajaí & 1982 & - & - & 13.308 & 13.268 & 11.247 & 14.792 \\
\hline Iracema & 1994 & - & - & - & - & 4.781 & 8.696 \\
\hline Caracaraí & 1955 & - & - & 8.900 & 9.378 & 14.286 & 18.398 \\
\hline Rorainópolis & 1995 & - & - & - & - & 17.393 & 24.279 \\
\hline Pres. Figueiredo & 1981 & - & - & 7.089 & 9.842 & 17.394 & 27.175 \\
\hline Rio Preto da Eva & 1981 & - & - & 6.519 & 9.629 & 17.582 & 25.719 \\
\hline Manaus & 1856 & 311.622 & 633.383 & $1.011,510$ & $1.154,330$ & $1.405,835$ & $1.802,014$ \\
\hline
\end{tabular}

Fonte: IBGE (2010). - Não era considerado município ou não há informação disponível. 


\section{Material e equipamentos}

Para a análise do desflorestamento foram utilizadas imagens do sensor Multispectral Scanner Subsystem (MSS) do satélite LANDSAT 2 e 3 para o ano de 1978, ou datas próximas de acordo com a disponibilidade e a menor cobertura de nuvens (Tabela 2). Para o ano de 1988 foram empregadas imagens do sensor Thematic Mapper (TM) do satélite LANDSAT
5. Para os anos de 1997 e 2008, foram empregados as imagens e os mapas do Programa de Cálculo do Desflorestamento da Amazônia (INPE/PRODES). Os dados cartográficos utilizados foram na escala de 1:250.000, tais como: mapas de rodovias, sede municipal e vegetação do banco de dados do IBGE/ SIPAM (2005) e CPRM (2005). Para o processamento e análise dos dados foram utilizados os softwares ArcMap/ArcGIS e Trackmaker.

Tabela 2: Cenas LANDSAT utilizadas na pesquisa.

\begin{tabular}{|c|c|c|c|c|c|}
\hline Satélite/sensor & Data & Orbita & Ponto & Bandas espectrais/arquivos & Resolução espacial \\
\hline LS-2 - MSS & $03 / 07 / 1979$ & 248 & 61 & \multirow{5}{*}{$4,5,6$} & \multirow{5}{*}{$79 \mathrm{~m}$} \\
\hline LS-3 - MSS & $03 / 07 / 1979$ & 248 & 62 & & \\
\hline LS-2 - MSS & $02 / 10 / 1979$ & 249 & 58 & & \\
\hline LS-2 - MSS & $07 / 02 / 1980$ & 249 & 59 & & \\
\hline LS-3 - MSS & $05 / 08 / 1978$ & 249 & 60 & & \\
\hline LS-5 - TM & $12 / 07-1987$ & 231 & 59 & \multirow{6}{*}{$\begin{array}{c}\text { Vermelho - 3, } \\
\text { Infravermelho próximo } 4 \\
\text { Infravermelho médio } 5\end{array}$} & \multirow{6}{*}{$30 \mathrm{~m}$} \\
\hline LS-5 - TM & $08-03-1988$ & 231 & 60 & & \\
\hline LS-5 - TM & $15-08-1988$ & 231 & 61 & & \\
\hline LS-5 - TM & $15-08-1988$ & 231 & 62 & & \\
\hline LS-5 - TM & $09-10-1988$ & 232 & 58 & & \\
\hline LS-5 - TM & $09-10-1988$ & 232 & 59 & & \\
\hline LS-5 - TM & \multirow{6}{*}{$\begin{array}{c}\text { 1997/2008 } \\
\text { INPE/PRODES }\end{array}$} & 231 & 59 & \multirow{6}{*}{$\begin{array}{c}\text { Arquivos no formato } \\
\text { shapefile }\end{array}$} & \multirow{6}{*}{$\begin{array}{c}60 \mathrm{~m} \\
\text { (origem) }\end{array}$} \\
\hline LS-5 - TM & & 231 & 60 & & \\
\hline LS-5 - TM & & 231 & 61 & & \\
\hline LS-5 - TM & & 231 & 62 & & \\
\hline LS-5 - TM & & 232 & 58 & & \\
\hline LS-5 - TM & & 232 & 59 & & \\
\hline
\end{tabular}

\section{Procedimentos metodológicos}

Para a análise do desflorestamento no entorno da BR-174 no trecho entre as capitais Manaus/AM a Boa Vista/RR foi considerada uma faixa de $20 \mathrm{~km}$ (10 $\mathrm{km}$ para cada lado da rodovia). A determinação desta faixa se dá em função de diversos estudos que descrevem que a maior parte do desflorestamento ocorre nas proximidades das estradas, em uma faixa média de até $5 \mathrm{~km}$ (SOARES FILHO, 1998; LAURANCE, et al., 2001; SOUZA Jr et al., 2004; FEARNSIDE, 2005; FERREIRA, et al., 2005)

A metodologia de análise de imagens foi realizada nas seguintes etapas: seleção de imagens, correção geométrica e classificação. As imagens do PRODES de 2008 e pontos de controle obtidos em campo com GPS foram utilizados para georreferenciar as imagens MSS (1978) TM (1988). Para tanto, foi utilizado o modelo polinomial de primeira ordem. $\mathrm{O}$ processamento das imagens de 1978 apresentaram um Erro Médio Quadrático (EMQ) com média de 1,226 pixel, com EMQ máximo de 1,582 pixels e mínimo de 0,873 pixels. Para as imagens do ano de 1988 o EMQ apresentou média de 0,658 pixel, com máximo de 0,789 pixels e mínimo de 0,521 pixels.

Os mapas de desflorestamento para os anos de 1978 e 1988 foram elaborados a partir da classificação das imagens MSS e TM, a partir da classificação híbrida (MOREIRA, 2001), com uso do classificador Máxima Verossimilhança e correção dos erros pela interpretação visual na tela do computador. Na classificação foram consideradas as seguintes classes: floresta (floresta primária), desflorestamento (pastagem, solo exposto, estradas, área urbana, vegetação secundária), savana (cerrado, campos alagados), corpos d'água (rios, lagos) e nuvem (nuvem e sombra). Por fim, foram realizadas as etapas de elaboração de mosaicos dos mapas de desflorestamento e comparação dos resultados com os mapas de vegetação do IBGE/ SIPAM (2005). Para compatibilizar os dados da série histórica de desflorestamento de 1978 a 2008 foram considerados apenas os polígonos maiores que 0,0625 
$\mathrm{km}^{2}(6,25 \mathrm{ha})$ de acordo com a metodologia do INPE/ PRODES (CÂMARA et al, 2009).

O trabalho de campo baseu-se numa viagem de Manaus/AM a Boa Vista/RR, passando pelos municípios ligados pela BR-174, em agosto de 2010. Nesta etapa foi utilizado um GPS Garmin 76 Cs $x$ conectado a um notebook. O software Trackmaker permitiu a navegação em tempo real sobre um mosaico de imagens TM/LANDSAT de 2008, o que possibilitou mapear, descrever e conferir, em toda a extensão da rodovia BR-174, as áreas com desflorestamento e o uso e cobertura da terra. Na etapa seguinte do estudo foi analisado o desflorestamento em função da distância da BR-174, considerando a área total desflorestada no incremento de cada $1 \mathrm{~km}$ da rodovia, até a extensão de $10 \mathrm{~km}$.

\section{RESULTADOS E DISCUSSÃO}

A extensão total da rodovia BR-174 percorrida neste estudo foi de $750 \mathrm{~km}$ e uma área total de 14.814 $\mathrm{km}^{2}$. Ao longo dos 30 anos de análise, observou-se um elevado crescimento na área desflorestada (Figuras 2 e 3), passando de $622,15 \mathrm{~km}^{2}$ em 1978 para $2.618,58$ $\mathrm{km}^{2}$ em 2008, totalizando $321 \%$ de aumento.

Figura 2: a) Desflorestamento acumulado na área do estudo. b) Tamanho dos polígonos de desflorestamento entre os anos de 1978 a 2008.
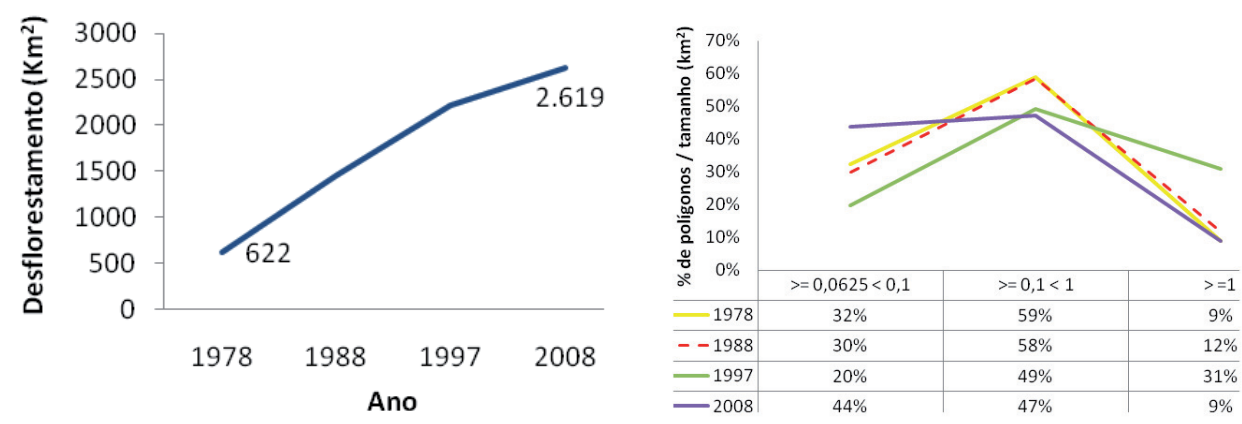

Figura 3: Evolução do desflorestamento ao longo da rodovia BR-174 (1978 a 2008).

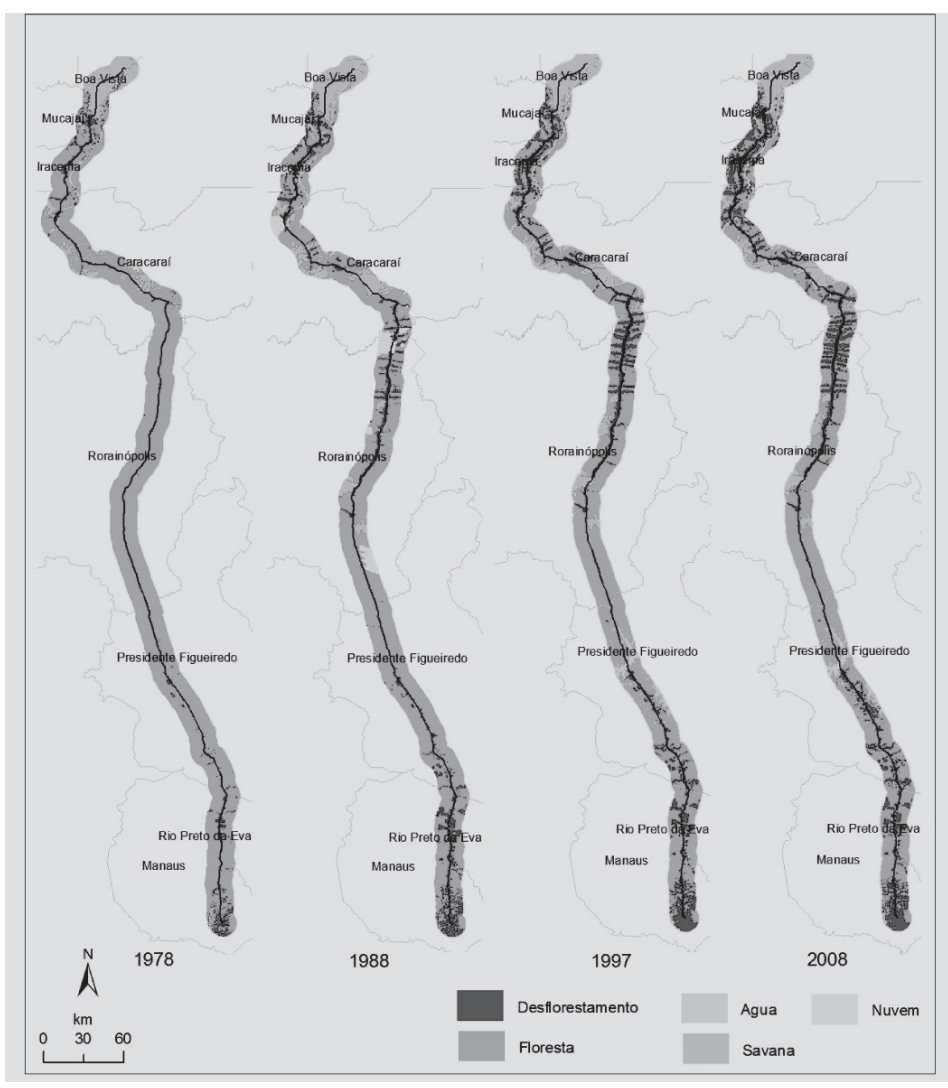

Soc. \& Nat., Uberlândia, ano 23 n. 3, 513-528, set/dez. 2011 
A análise do tamanho dos polígonos de desflorestamento demonstrou uma preponderância de áreas entre 0,1 a $1,0 \mathrm{~km}^{2}$ (Figura 2b). Os polígonos de desflorestamento mapeados para os anos de 1978 e 1988 somam aproximadamente 60\% e em 1997 e 2008, cerca de $50 \%$ estão dentro desta mesma faixa de tamanho (Figura 2b). Em todos os anos estudados, houve um aumento dos polígonos com desflorestamento maiores que $0,1 \mathrm{~km}^{2}$, sugerindo que na região as propriedades estão sendo ampliadas.

O desflorestamento ao longo da BR-174, em praticamente todos os municípios de Roraima e Amazonas, apresenta uma queda acentuada a partir das faixas mais próximas da rodovia para as faixas mais distantes (FIGURA 4). Este resultado confirma o que diversos estudos sobre o desmatamento na Amazônia descrevem, ou seja, a distribuição do desflorestamento possui carater exponencial em relação à distância da estrada principal (SOARES FILHO 1998; LAURANCE et al., 2001; FERREIRA et al., 2005; BRANDÃO Jr. et al., 2007; VIANA; FONSECA, 2009). O Município de Boa Vista/ RR, no entanto se constitui uma exceção, uma vez que o desflorestamento aumenta a uma distância de $6 \mathrm{~km}$ da rodovia devido à característica da vegetação na região, grande parte coberta por savanas e pequenas áreas de florestas mais distantes da BR-174.

Figura 4: Desflorestamento por município ao longo da BR-174 com aplicação das faixas de distâncias a cada 1 km no entorno da rodovia.
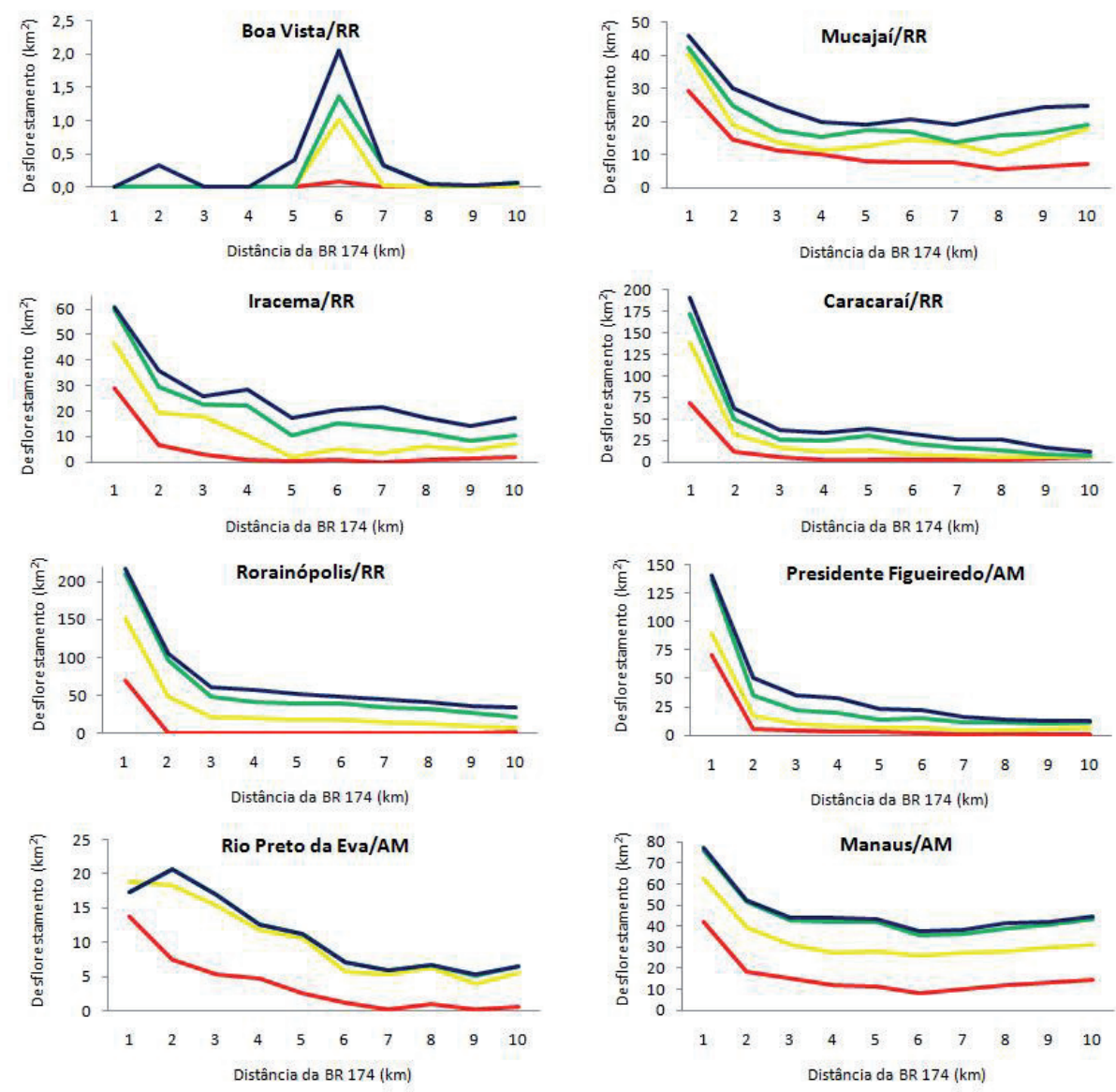

一Desfl_1978 —Desfl_1988

-Desfl_1997 —Desfl_2008

Soc. \& Nat., Uberlândia, ano 23 n. 3, 513-528, set/dez. 2011 
No estado de Roraima, avalia-se que o desflorestamento esteja associado às atividades da pecuária, mineração, agricultura, extração de madeira e obras. Estas atividades foram intensificadas a partir da década de 1970 quando ocorreram grandes fluxos migratórios para este estado, com a ocupação das margens das rodovias pelos primeiros migrantes e, posteriormente, nos anos de 1980, sendo abertas vicinais para assentar a nova geração de migrantes (BARROS, 1996). O uso da terra na região, nas décadas de 1980 e 1990, era definido pela agricultura, coleta de castanha, extração de madeira e pecuária, a produção agrícola era escoada para os mercados de Boa Vista/RR e Manaus/AM. Devido à distância desses mercados, era difícil a expansão da produção. Portanto, a promessa de asfaltamento das rodovias BR-174 e BR-210 era uma forma de valorização da agricultura comercial (BARROS, 1996).
Conforme Barros (1996), em todo estado de Roraima houve evasão e abandono de terras entre os anos de 1988 a 1993. A partir de 1993, novos imigrantes surgiram devido aos investimentos públicos em educação, energia, recuperação de pontes e estradas, etc. Entre 1990 a 1995, o INCRA obteve 104 inscrições em dois grandes Projetos de Assentamento Rural na Microrregião do Sudeste de Roraima, os Projetos de Assentamento Rápido do Jatapu e o Jauapery. Nestas áreas de assentamentos, também conhecido como agrovilas, cujo módulo rural é de 60 ha, pratica-se agricultura de subsistência de mandioca, milho, feijão, banana e arroz de sequeiro (IBGE, 2009).

Quando analisado o desflorestamento por município, verifica-se que Rorainópolis/RR apresentou a maior área, sendo $72,19 \mathrm{~km}^{2}$ em 1978 e $695 \mathrm{~km}^{2}$ em 2008, um aumento de $862 \%$ (FIGURA 5).

Figura 5: Desflorestamento na faixa de $20 \mathrm{~km}$ nos municípios da rodovia BR-174.

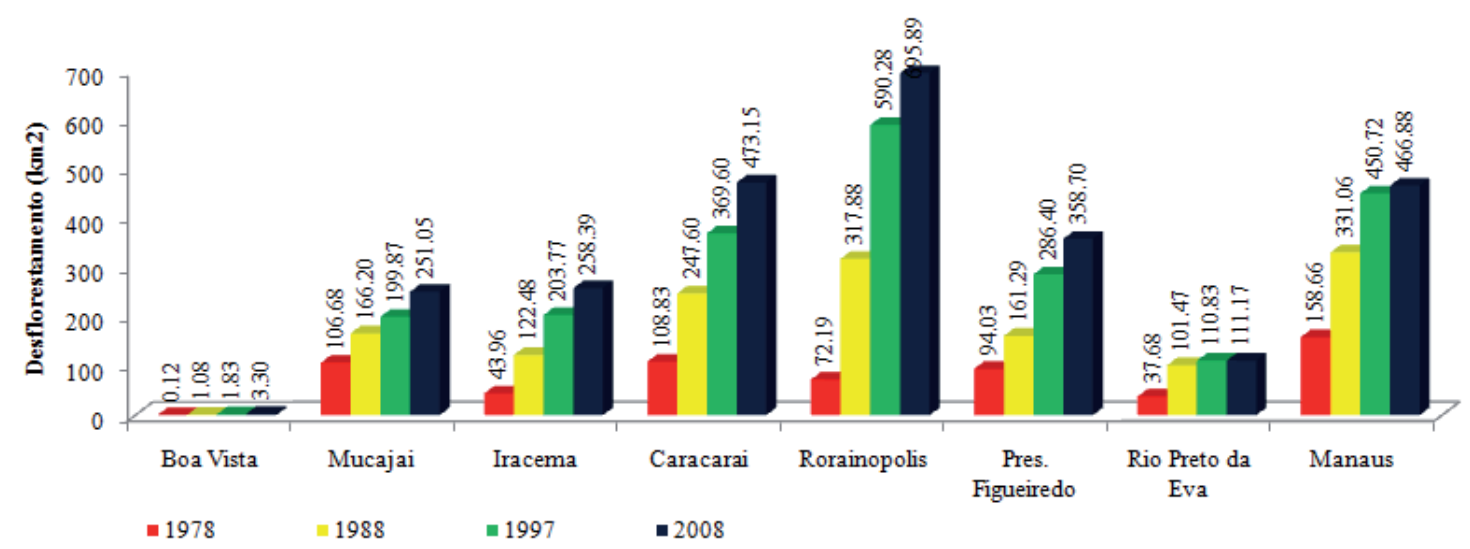

Durante o trabalho de campo foi possível observar no município de Rorainópolis/RR, algumas serrarias ao longo da rodovia BR-174. Segundo Barbosa (1990), o pólo madeireiro do Sul de Roraima era localizado entre os municípios de São João da Baliza/ RR e São Luiz do Anauá/RR, cidades localizadas ao longo da rodovia BR-210, onde se concentrava o maior estoque de madeiras, sendo disponibilizado pela abertura de Projetos de Assentamentos. A partir da década de 1990, o pólo madeireiro se deslocou para Rorainópolis/RR, cidade sede situada às margens da BR-174 e dentro do Projeto de Assentamento Dirigido
Anauá (BARBOSA et al., 2008). Segundo os autores, essa transferência foi possível devido à facilidade do transporte da madeira para os mercados de Manaus/ AM e Boa Vista/RR, com o asfaltamento da BR-174 e pela disponibilidade de madeiras em novas frentes de colonização no Sul de Roraima, devido ao declínio dos estoques verificados anteriormente no pólo localizado às margens da BR-210.

Conforme Barni (2009), as atividades de exploração e comercialização de madeiras em Rorainópolis/RR estão ligadas a forte presença de madeireiros vindos anualmente de outros estados visando 
a exploração florestal, muitos dos quais realizam o transporte das toras para as serrarias durante a noite para burlar a fiscalização. Estas afirmações têm relevância quando comparadas aos dados agropecuários do IBGE (2009), em que Rorainópolis aparece como o maior produtor (extração e comercialização) de madeiras em toras, sendo $32.500 \mathrm{~m}^{3}$. No entanto, não se pode atribuir o desflorestamento na região apenas a um único fator, pois várias áreas foram criadas para assentamentos rurais onde são realizadas atividades agrícola e pecuária.

O município de Rorainópolis apresentou 97\% do desflorestamento de 1978 até $1,0 \mathrm{~km}$ de distância da rodovia (Figuras 4 e 6). Esta evidência reflete os Projetos de Assentamento feitos pelo governo na década de 1970, uma vez que sua criação ocorreu às margens da BR-174 (BARROS, 1996). Para esse autor, na década de 1980 , foram abertas vicinais para alojar os novos migrantes, o que se verifica na queda significativa nas proximidades da rodovia, revelando um significativo aumento nas faixas mais distantes, como observado em 2008, onde o desflorestamento caiu para $31 \%$ na faixa de $1,0 \mathrm{~km}$ (Figura 4). Outro fato importante foi o aspecto econômico dos municípios com base nas grandes propriedades situadas nas margens da rodovia BR-174; pode-se verificar: propriedades produtoras (pecuária e agricultura), terras abandonadas e terras sem condição de uso devido ao alagamento do terreno. Durante o trabalho de campo foi possível visualizar áreas de desflorestamento nas margens da rodovia BR-174 associadas a instalações de famílias, loteamentos, fazendas abandonadas, pastagens, agricultura, pecuária, queimadas e abertura de ramais.

Figura 6: Desflorestamento acumulado ao longo da rodovida BR-174 até 2008, em Roraima. a) Municípios de Caracaraí, Iracema, Mucajaí e Boa Vista. b) Município de Rorainópolis.
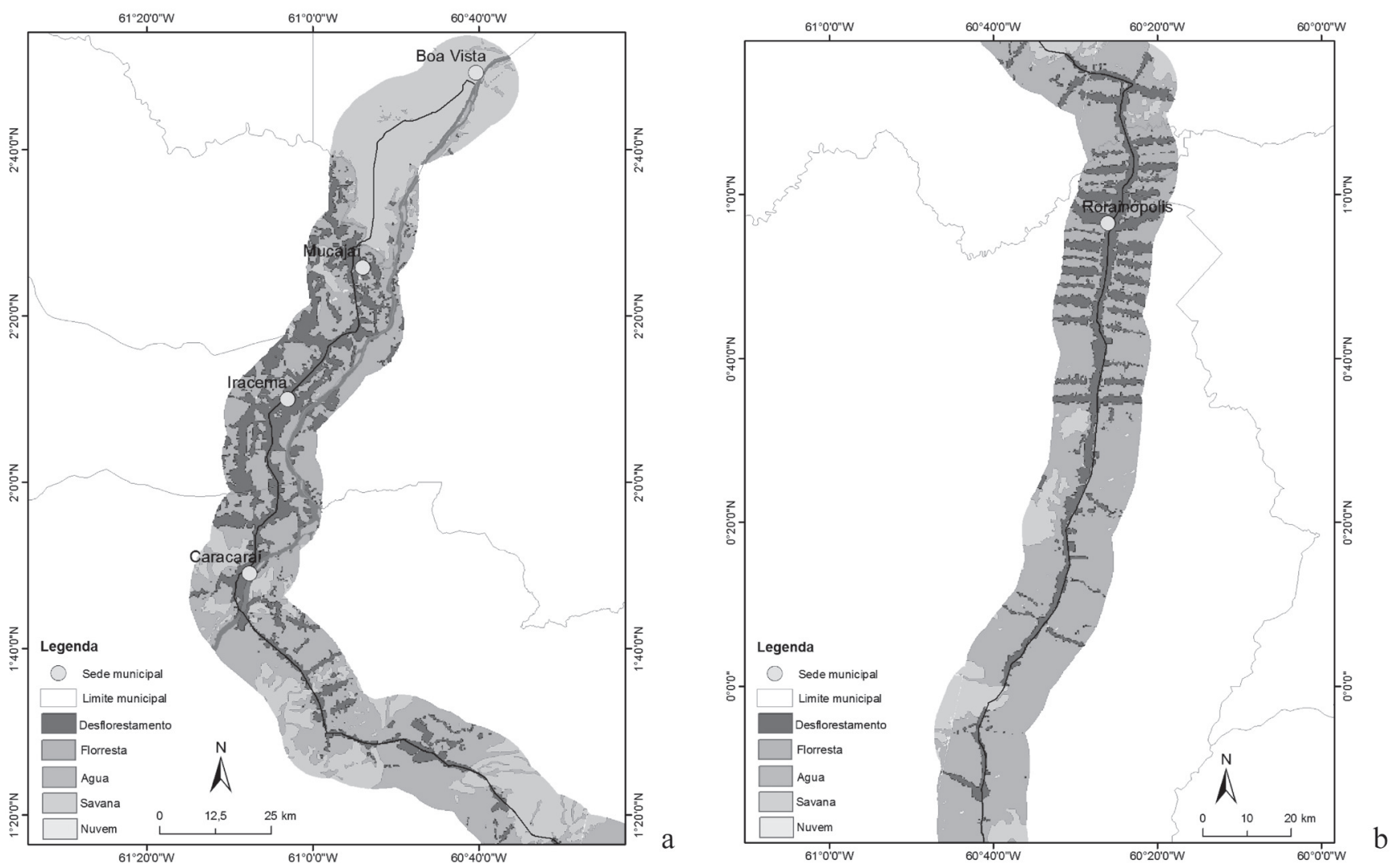

Soc. \& Nat., Uberlândia, ano 23 n. 3, 513-528, set/dez. 2011 
Em Boa Vista/RR, os resultados das análises do deflorestamento apontam a menor área em 1978 $\left(0,12 \mathrm{~km}^{2}\right)$ e em $2008\left(3,30 \mathrm{~km}^{2}\right)$ (Figura 5). O grande aumento do percentual (2.650\%) do desflorestamento nesta capital entre 1978 e 2008, não representa grande impacto quando comparados com a área dos demais municipios da área de estudo. Boa Vista teve seu crescimento (1940-1980), primeiramente, com a criação do municipio de Caracaraí (1955) - que passava a desempenhar importante papel de escoamento e recebimento de mercadorias, em seu porto no Rio Branco. Na decada de 1970, ocorreu uma expansão periférica, principalmente, devido a implantaçao do $6^{\circ} \mathrm{BEC}$, e posteriormente, veio o boom do garimpo de diamantes, que apesar de exitir desde o final da década de 1930, seu grande momento ocorreu no final dos anos de 1980 (BARROS, 1995). Entre 1987 e 1990, ocorreu um grande fluxo migratório estimulado pela busca do ouro nos garimpos de Roraima, a população de Boa Vista quase dobrou, passando de $72.758 \mathrm{em} 1987$ para 115.247 em 1990 (IBGE, 1990). Boa Vista passou de um uso da terra exclusivamente baseado na pecuária extensiva para um uso diversificado que inclui uma pecuária mais moderna e a policultura (IBGE, 2009).

No municipio de Mucajaí/RR, apesar de manter os padrões de desflorestamento nos primeiros quilometros próximos a rodovia (Figuras 4 e 6), observa-se um crescimento a partir da faixa dos 6 $\mathrm{km}$ distantes da rodovia, sobretudo, no ano de 2008. Nos primeiros quilômetros de distância da rodovia, o desflorestamento foi de $41 \%$ até $2 \mathrm{~km}$ em 1978, e passou para $30 \%$ em 2008 sendo que neste ano, a última faixa de distância somava $20 \%$ (distantes 9 e $10 \mathrm{~km}$ ) (Figura 4). Isto revela a expansão das propriedades para além das das margens da BR-174. Em 1978, o desflorestamento em Mucajái foi de 106,68 $\mathrm{km}^{2}$ e passou para $251,05 \mathrm{~km}^{2}$ em 2008 (Figura 5), um acréscimo de $135 \%$, ficando este com a menor taxa de crescimento entre os municípios analisados. $\mathrm{Na}$ avalição do desflorestamento, pode-se associar, também, a pecúária e o extrativismo. Na pecuária, Mucajaí aparece como o terceiro maior produtor de bovinos com 30.100 cabeças e, na extração de madeiras de tora, é o segundo, com $11.000 \mathrm{~m}^{3}$ (IBGE, 2011).

Neste estudo, Iracema/RR foi o município com a maior área desflorestada, cerca de $43,96 \mathrm{~km}^{2}$
$(8,11 \%)$ no ano de 1978 passando para $258,39 \mathrm{~km}^{2}$ (47,68\%) em 2008 (Figura 5) um aumento de 488\%. Do total de desflorestamento, $82 \%$ concentravam-se até $2 \mathrm{~km}$ de distância da rodovia em 1978 (Figuras 4 e 6), sendo 66\% no primeiro quilômetro. Em 2008, esse percentual caiu para $37 \%$ de desflorestamento até o $2 \mathrm{~km}$. O efetivo de bovino, apontado em Iracema, sendo o maior rebanho (210.501 cabeças), pode ter influenciado no desflorestamento desse município, que também pode ser verificado em campo, nas grandes propriedades pecuaristas nas margens da rodovia.

O desflorestamento no município de Caracaraí/RR (Figura 5) foi de 108,83 $\mathrm{km}^{2} \mathrm{em} \mathrm{1978,} \mathrm{sendo}$ $63 \%$ na faixa de $1 \mathrm{~km}$ de distância da rodovia, e em 2008 , chegou a $473,15 \mathrm{~km}^{2}$, sendo que $40 \%$ na primeira faixa, um aumento de $335 \%$ do total desmatado (Figuras 4 e 6). Esse aumento do desflorestamento pode estar associado a crescente expansão da população rural nas últimas décadas, podendo também estar associado a pecuária, uma vez que o município registrou o quarto maior rebanho bovino $(28.000$ cabeças) (IBGE, 2011). Além disso, foi o segundo município quanto as áreas destinadas aos proprietários individuais (128.319 ha). A produção de madeira em toras teve a maior reprentatividade, sendo $3.400 \mathrm{~m}^{3}$ (IBGE, 2011).

Entre os municípios estudados no Amazonas (Figura 7), Manaus/AM aparece como com maior área desflorestada, sendo 158,66 km² em 1978, passando para 466,88 km² em 2008 (Figura 5), um crescimento de $194 \%$. Em 1978, 27\% da área mapeada neste município estava desflorestadas, em uma distância de até $1 \mathrm{~km}$ da BR-174 (Figuras 4 e 7), em 2008, 17\% do desflorestamento estava no primeiro quilômetro, aumentando nas faixas mais distantes $(10 \%$ na faixa de $10 \mathrm{~km})$. A principal causa do desflorestamento em Manaus está associada ao crescimento demográfico e a necessidade de ampliação das habitações na cidade (MARQUES; PINHEIRO, 2011). A crescente urbanização da cidade determinou que o desflorestamento se deslocasse para faixas mais distantes, nas margens da BR-174 onde encontram-se construções de condomínios residenciais. Contudo, ainda, existem várias propriedades rurais situadas nas margens da rodovia BR-174 no sentido Norte em direção a cidade de Presidente Figueiredo. Segundo Lucas et al. (1998), 
o desflorestamento na área rural de Manaus, ao longo da BR-174, ocorreu principalmente no final dos anos de 1970 e 1980, sendo que os primeiros latifúndios foram criados em 1976 seguidos da construção da rodovia. Para remover os restos de madeira foi utilizada a queimada durante a operação inicial de derrubada e após o desflorestamento a maioria das áreas foi sujeita ao uso reduzido ou moderado (LUCAS et al, 1998).

O municipio de Rio Preto da Eva/AM apresentou 37,68 $\mathrm{km}^{2}$ de desflorestamento em 1978, alcançando $111,17 \mathrm{~km}^{2}$ no ano de 2008 , uma taxa de crescimento de $195 \%$ (Figura 5). Do total de desflorestamento, $37 \%$ aparece no primeiro quilômentro em 1978, e cai para 16\% em 2008 (Figuras 4 e 7), no entanto, percebe-se, principalmente em 2008, uma tendência crescente do desflorestamento nas faixas mais distantes da rodovia. A este fato, sugere que a dinâmica das alterações na paisagem do município tem mais influência da rodovia AM-010 do que a BR-174. Em Rio Preto da Eva/AM, diversas áreas rurais com desflorestamentos ocorreram no final da década de 1970 e início dos anos 80, com os primeiros latifúndios criados em 1976 seguindo a construção da rodovia BR 174 (LUCAS et al., 1998).

De acordo com os dados do IBGE (2011), Rio Preto da Eva teve o maior destaque na produção de carvão vegetal, sendo produzidos 487 toneladas e o maior produtor de lenhas com $57.752 \mathrm{~m}^{3}$. Silva (2006) analisou 12 propriedades produtoras de carvão vegetal que possuem em média 1 a 2 fornos, com a produçao média de $684 \mathrm{~kg}$ de carvão por forno, num período entre 8 a 12 dias. Segundo a autora, os produtores retiram a lenha de suas propriedades alegando que seus lotes ainda estão em fase de desflorestamento para plantio do roçado, e para não perder a madeira derrubada, aproveitam na produção de carvão. No entanto, cada lote possui 25 hectares, dos quais só podem ser desmatado 5 hectares, porém, a maioria dos produtores já estão alcançando esse limite. Outros produtores compram madeira de terceiros.

Figura 7: Desflorestamento acumulado ao longo da rodovida BR-174 até 2008, no Amazonas. a) Município de Presidente Figueiredo;

b) Municípios de Manaus e Rio Preto da Eva.
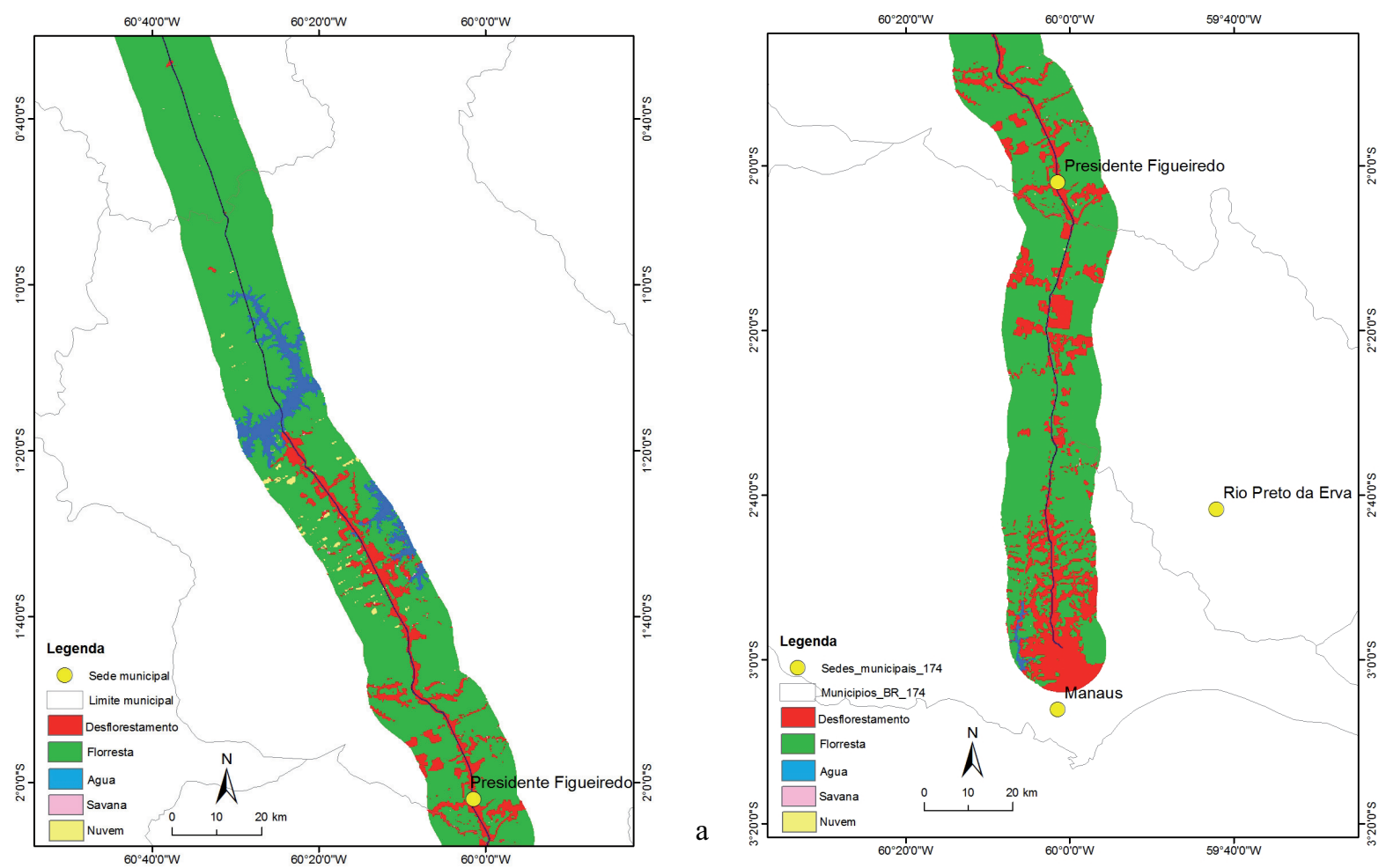

b 
Presidente Figueiredo/AM apresentou uma área desflorestada de $94,03 \mathrm{~km}^{2}$ em 1978 e 358,70 km² no ano de 2008 (Figura 5), um acréscimo de 281\%. $\mathrm{O}$ desflorestamemto no município concentra-se principalmente nas margens da BR-174 (Figuras 4 e 7), $75 \%$ do desflorestamento foi observado no primeiro quilômetro de distância em 1978 e 39\% em 2008. Nas áreas desflorestadas, se desenvolvem atividades relacionadas loteamentos, pastagens, agricultura de pequeno e médio porte, instalação de estabelecimentos comerciais e pequenos e médios empreendimentos turísticos. Além de pequenas pedreiras, em todos os casos, associados à abertura de ramais, desflorestamento e queimadas (SEMMA, 2006; REIS; PINHEIRO, 2010). Dentre os fatores potencialmente responsáveis pelo crescimento econômico do município é possível citar a construção e pavimentação da rodovia BR-174, que permitiu a maior parte do escoamento da produção por via terrestre no estado do Amazonas, a exploração de jazidas minerais na região de Pitinga e a Usina Hidrelétrica de Balbina (UHB) com sua infra-estrutura anexada (REIS; PINHEIRO, 2010).

\section{CONSIDERAÇÕES FINAIS}

O desflorestamento no entorno da rodovia BR-174, nos estados do Amazonas e Roraima, possui padrões semelhantes aos descritos na literatura para a região Amazônica, ou seja, a abertura de estradas e vicinais dissemina a ocupação humana e conseqüentemente o desflorestamento.

O desflorestamento no entorno da rodovia BR-174 no período de 1978 a 2008 apresentou um aumento de $321 \%$. No estado de Roraima a área estudada foi de $9.528,30 \mathrm{~km}^{2}$ e sua área desflorestada em 2008 chegou a $1.681,77 \mathrm{~km}^{2}$. No estado do Amazonas a área total estudada foi de $5.286,16 \mathrm{~km}^{2} \mathrm{e}$ a área desflorestada em 2008 foi de $936,74 \mathrm{~km}^{2}$. Nos dois Estados o desflorestamento representa aproximadamente $18 \%$ com relação à área estudada. Entre todos os municípios estudados, Rorainópolis apresentou a maior proporção de desflorestamento. Em 1978 eram aproximadamente $72 \mathrm{~km}^{2}$ e em 2008 registrou 695 $\mathrm{km}^{2}$. Porém, em termos percentuais de desflorestamento com relação à área estudada, o município de Iracema/RR apresentou a maior taxa, chegando em
2008 a aproximadamente $48 \%$.

Todos os municípios apresentaram a maior porção de desflorestamento nas faixas mais próximas à rodovia $\mathrm{BR}-17$, com exceção de Boa Vista/RR que possui florestas fora das proximidades da rodovia.

Avalia-se que as principais alterações na cobertura florestal da área estudada (1978 a 2008), se deram devido: a abertura da rodovia BR-174 e criação de propriedades em suas margens; aos assentamentos promovidos pelo INCRA; à promoção da atividade pecuária e agricultura; à extração de madeiras e recursos minerais; ao alagamento da área da Usina Hidrelétrica de Balbina; e por fim, ao crescimento urbano dos municípios, principalmente de Manaus e Boa Vista. O trabalho de campo permitiu confirmar o desflorestamento observado nas imagens orbitais analisadas e possibilitou caracterizar as propriedades rurais ao longo da rodovia.

As principais atividades econômicas desenvolvidas nos municípios por onde passa a BR-174, exceto Manaus, estão associadas à agricultura e a pecuária, atividades desenvolvidas em áreas anteriormente ocupadas por floresta. Em Manaus, o processo de desflorestamento ocorre principalmente na área urbana, associado ao crescimento urbano e à migração da população atraída pelas oportunidades de empregos nas indústrias da Zona Franca de Manaus.

Ainda que a construção e a pavimentação da BR-174 estejam associadas a processos de desflorestamento, a rodovia possui grande importância para a região, uma vez que foi responsável pela ligação terrestre entre as duas capitais (Manaus/AM e Boa Vista/ RR), possibilitou formar novas comunidades onde são desenvolvidas atividades econômicas e sociais. A criação de projetos de desenvolvimento sustentável é o grande desafio dos governos locais, para agregar valor aos empreendimentos já instalados e desenvolver novos modelos de uso e ocupação terrestre da região.

Estudos para melhorar as atividades socioeconômicas baseados na ciência e tecnologia direcionadas para o uso sustentável da biodiversidade regional deverão ser adotados, como alternativa aos assentamentos agropecuários de baixo nível tecnológico. Os saberes indígenas e tradicionais devem ser considerados, incorporando-os a um ciclo de crescimento econômico baseado na conservação da floresta, 
capaz de promover a melhoria da qualidade de vida e a conservação ambiental.

A criação de cooperativas pode ser uma alternativa para facilitar o desenvolvimento dos empreendimentos dos municípios por onde passa a rodovia, uma vez que proporcionaria um acesso direto aos recursos (tecnológicos, científicos, financeiros, armazenagem e escoamento da produção), minimização de processos burocráticos e da ação dos atravessadores bem como dos altos custos individuais. E, por fim, a necessidade de aplicação da legislação ambiental na região para garantir o uso sustentável dos recursos florestais e minerais.

\section{AGRADECIMENTO}

Ao Núcleo de Estudos e Pesquisas das Cidades na Amazônia Brasileira (NEPECAB/UFAM) que por meio do Conselho Nacional do Desenvolvimento Científico e Tecnológico - CNP (Processo 5755-17/2008-5) financiou os trabalhos de campos desta pesquisa.

\section{REFERÊNCIAS}

BAINES, S. G. A política indigenista governamental e os Waimiri-Atroari: administrações indigenistas, mineração de estanho e a construção da "autodeterminação indígena" dirigida. Revista de Antropologia, v. 36, p. 207-237, 1993a.

O território dos Waimiri-Atroari e o indigenismo empresarial. Série Antropologia, 138. 1993b. Disponível em: http://vsites.unb.br/ics/dan/Serie138empdf.pdf. Acesso em: 20 jan. 2011.

BARBOSA, R. I.; PINTO, F. S.; SOUZA, C. C. Desmatamento em Roraima: dados históricos e distribuição espaço-temporal. Relatório técnico. Ministério da Ciência e Tecnologia, Instituto Nacional de Pesquisas da Amazônia - INPA, Núcleo de Pesquisas de Roraima. 2008, 10p.
BARNI, P. E. Reconstrução e asfaltamento da rodovia BR-319: efeito "dominó" pode elevar as taxas de desmatamento no sul do estado de Roraima. 2009. 136f. Dissertação (Mestrado em Ciências de Florestas Tropicais) - Instituto Nacional de Pesquisas da Amazônia, 2009.

BARROS, N. C. Mobilidade populacional, fronteira e dinâmica das paisagens na Amazônia: o caso de Roraima. Cadernos de Estudos Sociais. n. 2, v. 12, p. 237-284, 1996.

. Roraima: paisagens e tempo na Amazônia Setentrional. Recife: Universitária, 1995, 272 p.

BATISTELA, M.; MORAN, E. F. A heterogeneidade das mudanças de uso e coberturas na Amazônia: em busca de um mapa da estrada. In: COSTA, W. M. da; BECKER, B.; ALVES, D. S. (Org.) Dimensões humanas da biosfera-atmosfera na Amazônia. São Paulo: Edusp, 2007. p. 65-80.

BRANDÃO Jr, A. O.; SOUZA Jr, C. M.; RIBEIRO, J. G. F.; SALES, M. H. R. Desmatamento e estradas não oficiais da Amazônia. In: XIII SIMPÓSIO BRASILEIRO DE SENSORIAMENTO REMOTO, 2007, Florianópolis: SC, Anais... Florianópolis: SC, 2007. p. 2357-2364.

CÂMARA, G.; VALERIANO, D.M.; SOARES, J.V. Metodologia para o cálculo da taxa anual de desmatamento na Amazônia Legal. São José dos Campos, 2006. 24p. Disponível em: www.obt.inpe.br/prodes . Acessado em: 19 jul. 2009.

FEARNSIDE, P. M. Desmatamento na Amazônia brasileira: história, índices e conseqüências. Megadiversidade, v. 1, n. 1, p. 113-123, 2005. 
FERREIRA, L. V.; VENTICINQUE, E.; ALMEIDA, S. O desmatamento na Amazônia e a importância das áreas protegidas. Estudos Avançados, v. 19, n. 53, p. 1-10, 2005.

HEMMING, J. Roraima: Brazil's northernmost frontier. London, Institute of Latin American Studies, 1990, 56p.

INSTITUTO BRASILEIRO DE GEOGRAFIA E ESTATÍSTICA (IBGE). Cidades. informações estatísticas, 2011. Disponível em: http://www.ibge.gov.br/ cidadesat.. Acesso em: 15 nov. 2010.

.Censos Demográficos: séries históricas. 2010 Disponível em: http://www.ibge.gov.br/home/estatistica/populacao/ defaulttab historicas.shtm. Acesso em: 15 ago. 2011.

. Uso da terra e a gestão do território no estado de Roraima. Relatório técnico, Rio de Janeiro, 46p. 2009.

INSTITUTO BRASILEIRO DE GEOGRAFIA E ESTATÍSTICA(IBGE)/SISTEMA DE PROTEÇÃO DA AMAZÔNIA (SIPAM). Mapa de vegetação. Escala 1:250.000, 2005.

LAURANCE, W. F., COCHRANE, M. A., BERGEN, S., FEARNSIDE, P. M., DELAMONICA, P., BARBER, C., D'ANGELO, S.; FERNANDES, T. The future of the Brazilian Amazon. Science, v. 291, p. 438-439, 2001.

LUCAS, R. M.; HONZÁK, M.; AMARAL, I.; CURRAN, P. J.; FOODY, G. M.; AMARAL, S. Avaliação da composição florística, biomassa e estrutura de florestas tropicais em regeneração: a contribuição do sensoriamento remoto. In: GASCON, C.; MOUTINHO, P. (Orgs.) Floresta Amazônica: Dinâmica, Regeneração e manejo. INPA, 1998, p. 61-82.
MARQUES, J. P. C.; PINHEIRO, E. S. O desflorestamento na metrópole da Amazônia Central: Manaus/ AM. In: XV SIMPÓSIO BRASILEIRO DE SENSORIAMENTO REMOTO, 2011. Curitiba, PR, Anais... Curitiba, PR. p.2876-2882.

MELO, V. F.; UCHOA, S. C. P. Impactos ambientais das atividades agrícolas em Roraima: Boa Vista, RR. Agro@mbiente, v. 2, n. 1, p. 102-106, 2008.

MOREIRA, M. A. Fundamentos do sensoriamento remoto e metodologias de aplicação. São José dos Campos: INPE, 2001.

OLIVEIRA, J. A. Cidades na Selva. Manaus: Editora Valer, 2000.

OLIVEIRA, J. A.; SCHOR, T. Manaus: transformações e permanências, do forte a metrópole regional. In: CASTRO, E. (Org.) Cidades na Floresta. São Paulo: Annablume, 2009. p. 41-98.

REIS, J. R. L.; PINHEIRO, E. S. Análise do desflorestamento em uma unidade de conservação de uso sustentável na Amazônia central. Revista Geografia, v. 35, n. 3, p. 623-640, 2010.

SECRETARIA MUNICIPAL DE MEIO AMBIENTE DE PRESIDENTE FIGUEIREDO (SEMMA/PF). Perspectivas de desenvolvimento sustentável e conservação ambiental. Visão global: subsídios do plano diretor. Presidente Figueiredo: SEMMA, 2006. 127p.

SERVIÇO GEOLÓGICO DO BRASIL (CPRM). Geobank. Banco de dados geográficos do estado do Amazonas, 2005. 
SILVA, A.R. Sistema de produção do carvão vegetal em duas áreas da estrada AM-010, Amazonas. 2006. 29f. Monografia (Graduação em Engenharia Florestal) - Universidade Federal do Amazonas UFAM, 2006.

SILVA, C. P. B. A.; SÁ, E. C. Planejamento sócio-ambiental estratégico prevenindo impactos e maximizando benefícios de obras rodoviárias em escala regional - o caso da BR-174/RR. In: SEMINÁRIO NACIONAL: Degradação e recuperação ambiental, 2003, Foz Iguaçu, PR. Disponível em: http://www. sobrade.com.br/eventos/2003/seminario/Trabalhos/003. pdf. Acesso em: 20 jun. 2009.

SOARES FILHO, B.S. Modelagem da dinâmica de paisagem de uma região de fronteira de colonização amazônica. 1998. 299f. Tese (Doutorado em Engenharia de Transporte) - Universidade de São Paulo, 1998.

SOUZA Jr, C.; BRANDÃO, A.; ANDERSON, A.; VERÍSSIMO, A. Avanço das estradas endógenas na Amazônia. Amazônia em Foco. Manaus, Imazon, 2004. Disponível em: <http://www.imazon.org.br/ upload/ea_1p.pdf>. Acessado em: 08 nov. 2010.

VIANA, J. S.; FONSECA, M. G. Expansão de estradas e desmatamento em unidades de conservação do município de Belterra, Pará. In: XIV SIMPÓSIO BRASILEIRO DE SENSORIAMENTO REMOTO. 2009, Natal, RN, Anais... Natal, RN, 2009. p. 15731579 . 